\title{
COMPARATIVE STUDY OF 0.5\% TIMOLOL AND 2\% DORZOLAMIDE IN PRIMARY OPEN ANGLE GLAUCOMA IN A TERTIARY CARE HOSPITAL
}

\author{
Padma L1, Veena D.R ${ }^{2}$, Rani Sujatha ${ }^{3}$, Asha $\mathrm{P}^{4}$
}

\section{HOW TO CITE THIS ARTICLE:}

Padma L, Veena D. R, Rani Sujatha, Asha P. “Comparative study of $0.5 \%$ timolol and $2 \%$ dorzolamide in primary open angle glaucoma in a tertiary care hospital". Journal of Evolution of Medical and Dental Sciences 2013; Vol2, Issue 35, September 2; Page: 6659-6663.

ABSTRACT: OBJECTIVES: To compare the IOP reducing efficacy and safety of $0.5 \%$ timolol and $2 \%$ dorzolamide in primary open angle glaucoma. MATERIAL AND METHODS: In this prospective, open labelled, randomised comparative study, 60 patients received either $0.5 \%$ timolol twice daily ( $\mathrm{n}=30$ ) or $2 \%$ dorzolamide twice daily $(n=30)$ for 6 months. IOP was measured every fortnight. RESULTS: The mean IOP reduction from baseline was $15.55 \mathrm{mmHg}$ for dorzolamide group and 13.45 for timolol group, but not statistically significant $(p=0.028)$. Dorzolamide group had higher incidence of adverse effects like ocular irritation compared to timolol group, but not statistically significant $(\mathrm{p}=$ 0.097). CONCLUSION: $0.5 \%$ timolol eye drops twice daily is non inferior in IOP lowering efficacy compared to $2 \%$ dorzolamide eye drops twice daily in patients with POAG. Incidence of adverse effects like ocular irritation was higher in dorzolamide group compared to timolol group.

KEY WORDS: dorzolamide, timolol, IOP-reducing drugs, POAG, retinal haemodynamics

INTRODUCTION: Glaucoma, a chronic, progressive and most often asymptomatic disease, is ranked as the leading cause of irreversible blindness worldwide by the World Health Organization. (1) Primary open angle glaucoma (POAG) is defined as a chronic optic neuropathy with characteristic changes in optic disc and visual field. (2)

POAG is estimated to affect about 6.48 million people. With an increase in life expectancy, this figure will increase to 16 million 2020. (3)

These numbers highlight the importance of understanding the disease, its natural history, and its underlying pathophysiology, so that we may try to establish effective methods of treatment and preventive measures to delay, or even arrest disease progression, thereby reducing visual morbidity.

At present, all resources are directed towards reduction of intraocular pressure (IOP), the only known causal and treatable risk factor for glaucoma. Topical drugs are commonly used to reduce IOP in the medical management of POAG.

The purpose of this study was to compare the IOP reducing efficacy and safety of $0.5 \%$ timolol and 2\% dorzolamide in POAG.

MATERIAL AND METHODS: This prospective open labelled randomised comparative study was carried out in out -patient department of ophthalmology at Dr. B.R. Ambedkar Medical College and Hospital during November 2009 and October 2010. It was approved by the Institutional Ethics Committee. Informed consent was taken from each patient before they enrolled in the study.

Patients $>40$ years of age of either sex who were newly diagnosed cases of POAG atleast in one eye were included in the study. 


\section{ORIGINAL ARTICLE}

Patients with acute angle closure glaucoma or narrow angle, pigmentary/exfoliation glaucoma, pregnant and lactating females, h/o hypersensitivity to study drugs, bradycardia, second or third degree heart block, bronchial asthma, COPD, CHF, severe renal impairment, PVD were excluded from the study.

60 cases of POAG were selected and divided equally into two groups based on simple random sampling. Detailed history was taken and a thorough examination of their general and systemic conditions was done. 30 patients were treated with $0.5 \%$ timolol eye drops twice daily and another 30 patients with $2 \%$ dorzolamide eye drops twice daily for 6 months.

Ocular improvement and effect of the drug were assessed by follow up every fortnight for 6 months. Each time IOP was measured using Perkins hand held tonometer and Schiotz tonometer. Two readings were taken to establish the gradual reduction and final IOP. The visual field defect was documented by Octopus and visual acuity by Snellen's chart both at the baseline and at the end of the study. All these details were recorded in a well designed proforma.

The data was analysed using descriptive statistical tool and comparison between the groups by student's't' test.

RESULTS: 60 patients were included in the study. 40(66.6\%) were male and 20(33.3\%) were females. They were classified into four age groups i.e. 41-50, 51-60, 61-70 and 71-80 years. Maximum numbers of patients (33.3\%) were in the age group of 51-60years.

The mean IOP across various time points is shown in table 1 . There was no much difference in efficacy between the two treatment groups. The mean IOP reduction from baseline is shown in table 2. It was $15.55 \mathrm{mmHg}$ for dorzolamide group and 13.45 for timolol group, but not statistically significant $(\mathrm{p}=0.028)$

Dorzolamide group had higher incidence of adverse effects like ocular irritation compared to timolol group, (table 3 ) but not statistically significant $(p=0.097)$.

\section{Comparative evaluation of efficacy: Mean IOP (mm Hg) across time points}

\begin{tabular}{|c|c|c|c|c|}
\hline Treatment group & Baseline & $\mathbf{4}^{\text {th }}$ week & $\mathbf{1 2}^{\text {th }}$ week & $\mathbf{2 4}^{\text {th }}$ week \\
\hline Timolol & 28.83 & 26.70 & 20.98 & 15.37 \\
\hline Dorzolamide & 31.67 & 30.87 & 25.18 & 16.12 \\
\hline
\end{tabular}

\section{Mean IOP change from baseline:}

\begin{tabular}{|c|c|c|}
\hline Treatment group & $\mathbf{1 2}^{\text {th }}$ week & $\mathbf{2 4}^{\text {th }}$ week \\
\hline Timolol & 7.85 & 13.46 \\
\hline Dorzolamide & 6.49 & 15.55 \\
\hline
\end{tabular}

\section{Comparative evaluation of safety:}

\begin{tabular}{|c|c|c|}
\hline Adverse effect & Timolol (\%) & Dorzolamide (\%) \\
\hline Ocular irritation & $1(3 \%)$ & $7(23 \%)$ \\
\hline Ocular pain & 0 & $3(10 \%)$ \\
\hline Blurring of vision & 0 & $1(3 \%)$ \\
\hline
\end{tabular}




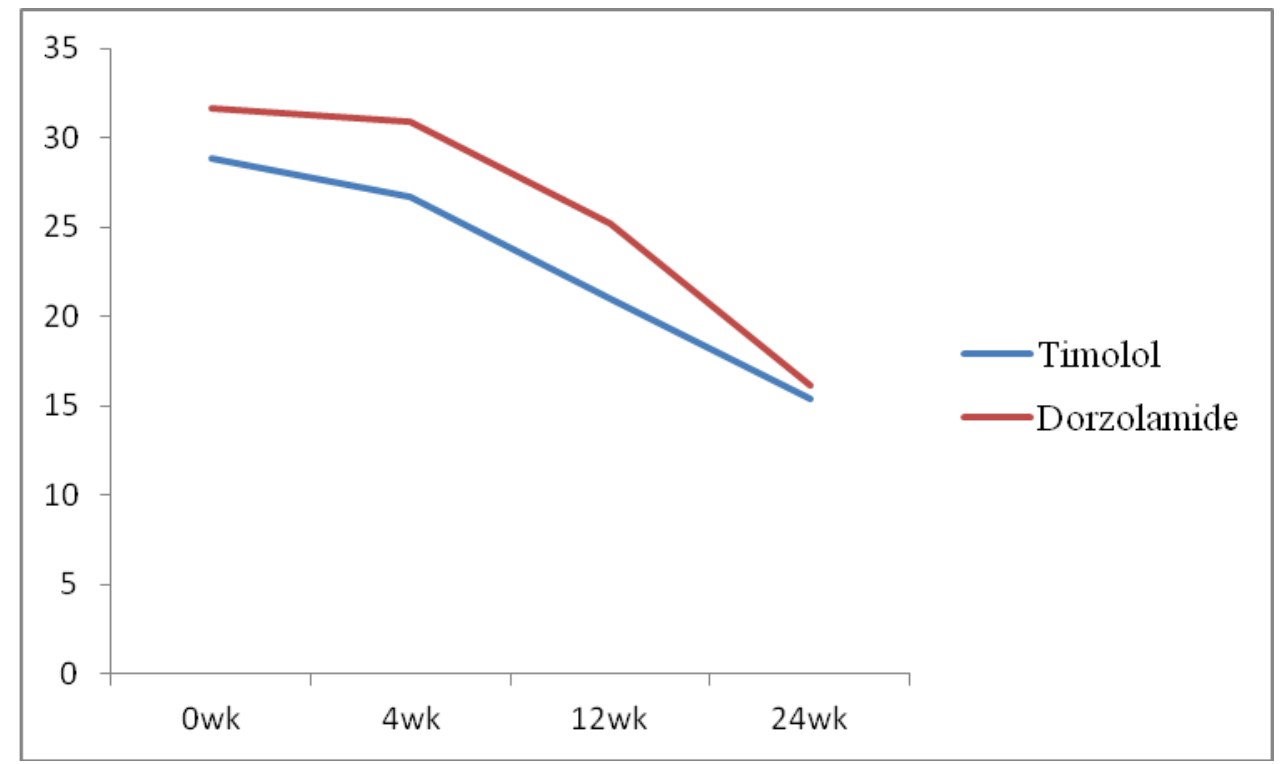

Mean IOP (mm Hg) across time points

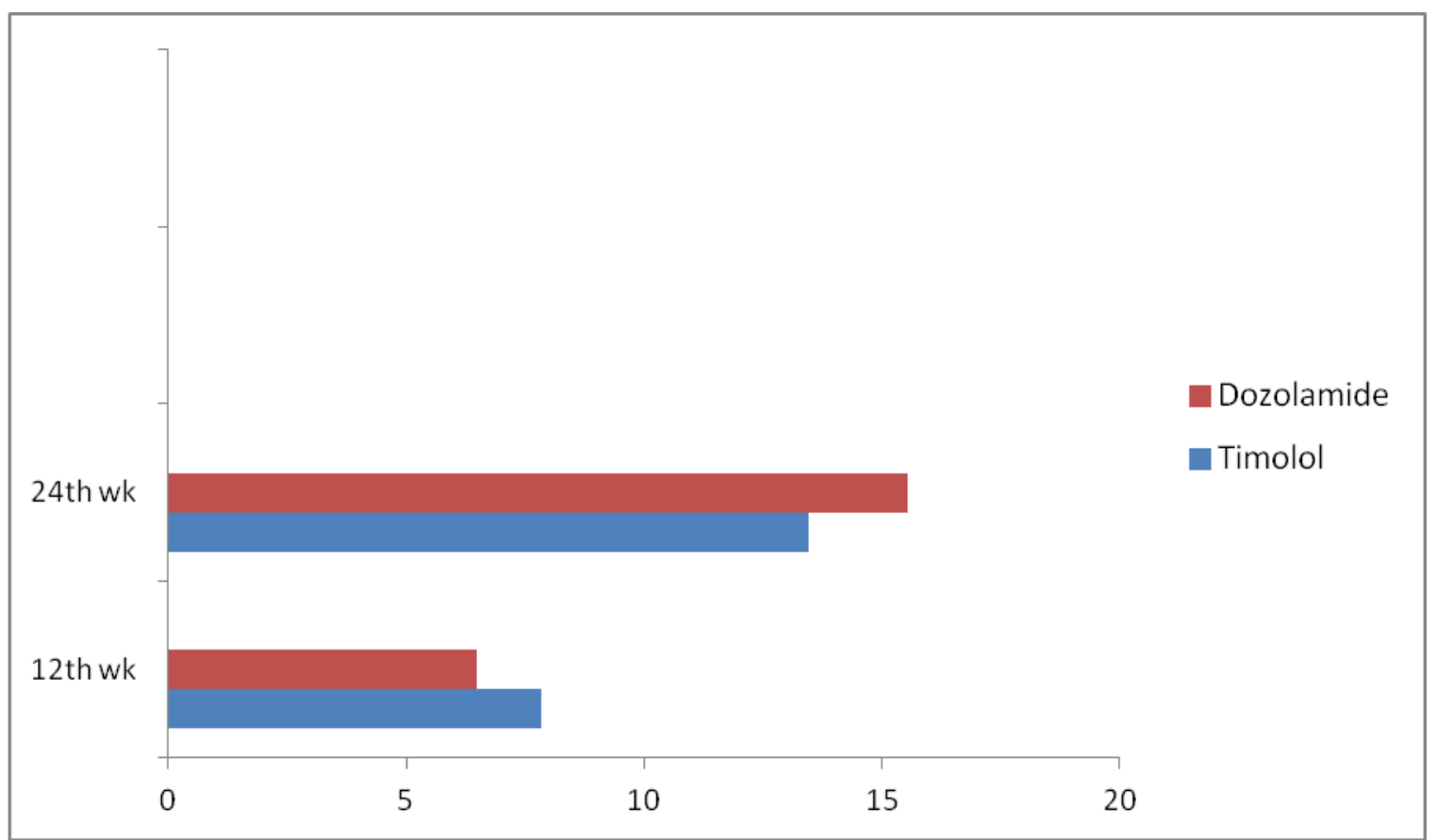

Mean IOP change from baseline (mmHg)

DISCUSSION: Timolol is a non-selective beta-blocker being used extensively world wide as a first line agent for the treatment of POAG and ocular hypertension. It acts by blocking beta-2 receptors in the ciliary processes and thus reducing aqueous production.

Dorzolamide is a topical carbonic anhydrase inhibitor. It slows the production of bicarbonates and thus decreases sodium and fluid transport which in turn reduces the secretion of aqueous humor. (4) 


\section{ORIGINAL ARTICLE}

The mean IOP reduction from baseline is shown in table 2. It was $15.55 \mathrm{mmHg}$ for dorzolamide group and 13.45 for timolol group, but not statistically significant ( $p=0.028)$.

Visual acuity and field of vision at the end of 6 months was same in both the treatment groups as recorded at the baseline.

Dorzolamide group had higher incidence of adverse effects like ocular irritation compared to timolol group (table 3), but not statistically significant $(p=0.097)$.

These findings are consistent with other studies conducted by Strahlman etal (5) and Fuchsjager G etal. (6) There are studies which indicate that dorzolamide, but not timolol, increases optic nerve head and choroidal blood flow in patients with POAG or ocular hypertension. (6) This effect may be associated with a preservation of visual fields in patients with glaucoma.

Monotherapy is frequently not sufficient for reaching the preset target IOP. Therefore ophthalmologists prescribe combination therapy to achieve adequate reduction in IOP (7). It also improves patient compliance. Most fixed dose combinations contain timolol as it can be dosed either once/twice daily and can be combined with prostaglandin analogues, adrenergic agonists and carbonic anhydrase inhibitors. ${ }^{(8)}$ The combination of timolol and dorzolamide significantly improves retinal haemodynamics in POAG. (9) Therefore FDCs if rational offer benefits of convenience, cost and safety.

CONCLUSION: $0.5 \%$ timolol eye drops twice daily is non inferior in IOP lowering efficacy compared to $2 \%$ dorzolamide eye drops twice daily in patients with POAG. Incidence of adverse effects like ocular irritation was higher in dorzolamide group compared to timolol group. Dorzolamide increases optic nerve head and choroidal blood flow in patients with POAG or ocular hypertension. This effect may be associated with a preservation of visual fields in patients with glaucoma.

\section{REFERENCES:}

1. Robin A, Grover DS. Compliance and adherence in glaucoma management. Indian J Ophthalmol 2011; 59:S93-96.

2. Yadav AK, Patel V. Drug use in primary open angle glaucoma: a prospective study at a tertiary care teaching hospital. Indian J Pharmacology 2013; 45(2):117-120.

3. George R, Vijaya L. First world glaucoma day, March 6, 2008: Tackling challenges in India. Indian J Ophthalmol 2008; 56:97-98.

4. Kohli, etal. Contemporary perspectives in Clinical Pharmacotherapeutics, $1^{\text {st }}$ ed. Elsevier publication, 2006, 577-607.

5. Strahlman E, Tipping R, Vogel R, etal. A double masked randomized 1-year study comparing dorzolamide, timolol and betaxolol. Arch Ophthalmol 1995; 113:1009.

6. Fuchsja"ger-Mayrl G, Wally B, Rainer G, etal. Effect of dorzolamide and timolol on ocular blood flow in patients with primary open angle glaucoma, British J Ophthalmol 2005:89(10):1293-1297.

7. Kass MA, Heuer DK, Higginbotham EJ, et al. The Ocular Hypertension Treatment Study: a randomized trial determines that topical ocular hypotensive medication delays or prevents the onset of primary open-angle glaucoma. Arch Ophthalmol. 2002; 120(6):701-713. 


\section{ORIGINAL ARTICLE}

8. Miguel A T, Stefano M, Guna L. Efficacy and safety of travoprost/timolol vs dorzolamide/timolol in patients with open-angle glaucoma or ocular hypertension. Clinical Ophthalmology 2009:3 629-636.

9. Costagliola C, Campa C, Parmeggiani F, et.al. Effect of $2 \%$ dorzolamide on retinal blood flow. A study on juvenile primary open angle glaucoma patients already receiving $0.5 \%$ timolol.British J Clinical Pharmacology 2007;63:376-379.

\section{AUTHORS:}

1. Padma L.

2. Veena D.R.

3. Rani Sujatha

4. Asha P.

\section{PARTICULARS OF CONTRIBUTORS:}

1. Professor and H.O.D, Department of Pharmacology, Dr. B.R. Ambedkar Medical College.

2. Associate Professor, Department of Pharmacology, Dr. B.R. Ambedkar Medical College.

3. Professor and H.O.D, Department of Ophthalmology, Dr. B.R. Ambedkar Medical College.

4. Post Graduate, Department of Pharmacology, Dr. B.R. Ambedkar Medical College.

\section{NAME ADRRESS EMAIL ID OF THE CORRESPONDING AUTHOR:}

Dr. Veena D.R, Associate Professor, Department of Pharmacology, Dr. B.R. Ambedkar Medical College, K.G. Halli, Bangalore - 560045 . Email - veena.dr@gmail.com

Date of Submission: 20/08/2013. Date of Peer Review: 21/08/2013. Date of Acceptance: 23/08/2013. Date of Publishing: 27/08/2013 